\title{
$\sim$

\section{Metodologias ativas nas aulas de Geografia no Ensino Médio como estímulo ao protagonismo juvenil}

\author{
Active methodologies in Geography classes in High School as a stimulus \\ to youth protagonism.
}

Ana Maria de Oliveira Pereira

Professora doutora na Universidade Federal da Fronteira Sul, Brasil.

anamaria.oliveira08@gmail.com - http://orcid.org/0000-0001-6276-4282

\section{Acacia Zeneida Kuenzer}

Professora doutora na Universidade FEEVALE, Novo Hamburgo, Rio grande do Sul, Brasil. acaciak4@gmail.com - http://orcid.org/0000-0001-9462-5818

\section{Adriano Canabarro Teixeira}

Professor doutor na Universidade de Passo Fundo, Passo Fundo, Rio Grande do Sul, Brasil. teixeira@upf.br - http://orcid.org/0000-0002-7941-3515

\section{Recebido em 03 de novembro de 2017}

Aprovado em 12 de janeiro de 2018

Publicado em 09 de outubro de 2019

\section{RESUMO}

O artigo é parte das construções teóricas e intervenções práticas realizadas em pesquisa qualitativa, que teve como propósito compreender como o uso das tecnologias digitais pode contribuir na construção do conhecimento geográfico dos estudantes do Ensino Médio, de modo a estimulá-los ao protagonismo juvenil. Os trabalhos foram orientados com base na seguinte problemática: Qual é o potencial existente no uso das tecnologias digitais da informação e comunicação para a construção do conhecimento geográfico no Ensino Médio com vistas ao estímulo do protagonismo social do jovem? Essa problemática foi delineada a partir da visão de que muitas vezes as disciplinas escolares parecem estar desconectadas do cotidiano dos estudantes. A pesquisa de caráter exploratório teve como procedimento o estudo de casos múltiplos, onde trabalhou-se com três professores de Geografia e suas respectivas turmas, totalizando sessenta estudantes. As atividades práticas da pesquisa foram conduzidas sob o método sala de aula invertida, com uso intensivo das tecnologias digitais. Com a realização da atividade constata-se que o uso das tecnologias digitais nas aulas proporciona maior envolvimento do estudante com o conteúdo e também estimula o protagonismo juvenil. Por outro lado, evidencia a necessidade da utilização de metodologias específicas para estas aulas, pois do contrário é grande a possibilidade de compreensão das tecnologias digitais apenas como mudança de suporte para desenvolvimento das atividades de aula.

Palavra-chave: Protagonismo Juvenil. Ensino de Geografia. Tecnologias Digitais 


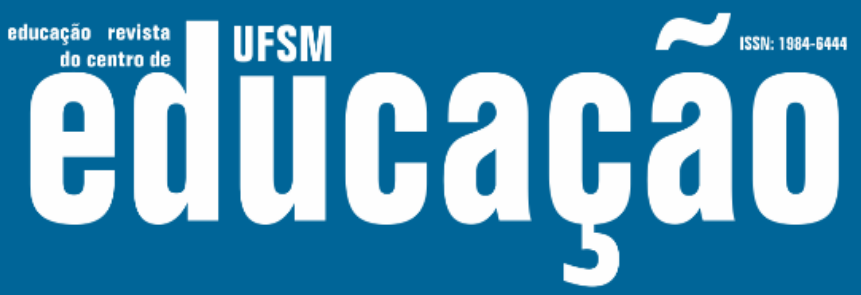

ISSN: 1984-6444 | http://dx.doi.org/10.5902/1984644429807

\section{ABSTRACT}

This article is part of the theoretical constructions and practical interventions occurred on the elaboration of the thesis which purpose was to comprehend how the use of digital technologies can contribute to the building of geographic knowledge of High School students, stimulating them to the youth protagonism. The tasks were oriented based on the following problematic: What is the potential existent in the use of digital technologies of information and communication to the building of geographic knowledge in High School attempting to stimulate the teenager's youth protagonism? This problematic was drawn based on the vision that, most of the time, school subjects seem to be disconnected from the students' daily lives. The exploratory research had as procedure the study of multiple cases, which included three Geography teachers and their respective classes totaling sixty students. The practical activities of the research were conducted by the method of the inverted classroom, with intensive use digital technologies. With this activity, it is noted that the using of digital technologies during class provides to the student a better involvement with the content, as well as the stimulation of youth protagonism. On the other hand, it clarifies the necessity of using specific digital technologies to these classes, for the opposite could increase the possibilities of comprehension of the digital technologies as an alternative to the development of the activities in class.

Keywords: youth protagonism; Geography teaching; Digital Technologies

\section{Introdução}

Este artigo é um recorte das construções teóricas e intervenções práticas realizadas durante a pesquisa qualitativa realizada em 2017. O propósito da tese foi compreender como o uso das tecnologias digitais pode contribuir na construção do conhecimento geográfico dos estudantes do Ensino Médio, de modo a estimulá-los ao protagonismo juvenil. Para tal norteou-se o trabalho com base na seguinte problemática: Qual é o potencial existente no uso das tecnologias digitais da informação e comunicação para a construção do conhecimento geográfico no Ensino Médio com vistas ao estímulo do protagonismo social do jovem? O desenho da problemática concretiza-se a partir da visão de que, muitas vezes, as disciplinas escolares parecem estar desconectadas do cotidiano dos estudantes.

Observa-se isso de modo muito claro no ensino da Geografia, que apesar de ter um caráter bastante dinâmico, pois estuda a complexa relação entre sociedade e 


\section{F HWM Eutloará

ISSN: 1984-6444 | http://dx.doi.org/10.5902/1984644429807

natureza, ainda utiliza muitos recursos de memorização nas aulas, em detrimento de outros como mapas, globos, fotos de satélite, Global Position System (GPS) e programas gratuitos disponíveis na internet para a construção do conhecimento geográfico. Uma aula de Geografia sem recursos visuais é um estímulo à memorização de informações e distancia-se completamente dos objetivos propostos pelo Ministério da Educação (MEC) nas Orientações Curriculares do Ensino Médio.

Conforme o disposto nesse documento, as aulas de Geografia devem proporcionar ao estudante condições de: "localizar, compreender e atuar no mundo complexo, problematizar a realidade, formular proposições, reconhecer as dinâmicas existentes no espaço geográfico, pensar e atuar criticamente em sua realidade tendo em vista a sua transformação" (BRASIL, 2006, p. 43).

Possibilitar aos estudantes condições para que possam associar os conteúdos vistos na escola em seu dia a dia é tornar a aprendizagem significativa, contribuindo para que tenham melhores condições de entender a sociedade e, sentindo-se parte integrante dela, atuar no sentido de sua transformação. Desta forma, os estudantes poderão desfrutar e também preservar o que está no seu entorno, pois, conforme Lacoste (2012, p. 230), "o mundo é ininteligível para quem não tem um mínimo de conhecimento geográfico".

Com esse intuito, realizou-se pesquisa de caráter exploratório, com abordagem quali-quantitativa, tendo como procedimento o estudo de casos múltiplos. Uma das atividades foi a intervenção nas turmas pesquisadas, na qual utilizou-se a metodologia ativa denominada "sala de aula invertida", que será relatada neste artigo. A intervenção foi conduzida a partir dos conteúdos que estavam sendo trabalhados pelo professor regente da turma, tendo como foco o vínculo do assunto com situações reais do dia a dia dos estudantes.

Os trabalhos foram realizados em três turmas do segundo ano do Ensino Médio, de três diferentes escolas públicas estaduais do município de Erechim, localizado no norte do Estado do Rio Grande do Sul, com seus respectivos professores de Geografia, totalizando sessenta estudantes.

O objetivo com a realização da atividade foi proporcionar condições para que os estudantes do Ensino Médio tivessem estímulo ao protagonismo nas aulas de 


\section{T WsM

ISSN: 1984-6444 | http://dx.doi.org/10.5902/1984644429807

Geografia, e por isso optou-se por utilizar um método ativo para a realização das aulas.

As atividades da pesquisa sob o método "sala de aula invertida" foram elaboradas e conduzidas pela pesquisadora. As aulas foram realizadas no laboratório de informática da escola, com auxílio de computadores e celulares conectados à internet. Cada turma foi dividida em grupos de no máximo cinco componentes, que realizavam suas anotações em um documento compartilhado com a pesquisadora. Por fim, os estudantes elaboraram e socializaram suas conclusões aos colegas, conforme a escolha de cada grupo.

Ao final do estudo foi possível concluir que o uso das Tecnologias Digitais da Informação e Comunicação (TDIC) nas aulas de Geografia do Ensino Médio estimula o protagonismo juvenil e resignifica o ato de aprender e o processo de construção do conhecimento devido às possibilidades proporcionadas.

O artigo está estruturado nos seguintes tópicos: 1) Introdução; 2) A "sala de aula invertida" na Geografia; 3) O protagonismo social do jovem, estudante do Ensino Médio; 4) Metodologias ativas na aula de Geografia estimulando o protagonismo juvenil; 5) Considerações finais.

\section{A "sala de aula invertida" na geografia}

As atividades de aula foram planejadas e desenvolvidas a partir da visão de que as metodologias necessariamente devem levar os alunos a relacionar-se com o conhecimento de forma significativa, assumindo o professor seu papel de mediador:

Se queremos que os alunos sejam proativos, precisamos adotar metodologias em que os alunos se envolvam em atividades cada vez mais complexas, em que tenham que tomar decisões e avaliar os resultados, com apoio de materiais relevantes. Se queremos que sejam criativos, eles precisam experimentar inúmeras novas possibilidades de mostrar sua iniciativa. (MORAN, 2015, p. 17).

Nas metodologias ativas, o intuito é combinar de maneira equilibrada as atividades com desafios e também informações contextualizadas. Essas metodologias, que também se adéquam às aulas mediadas pelas TDIC, propõem o foco na aprendizagem do estudante, desenvolvendo condições para que ele se 


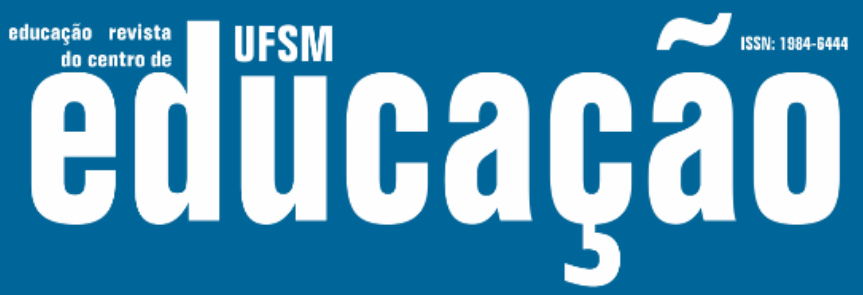

ISSN: 1984-6444 | http://dx.doi.org/10.5902/1984644429807

envolva no processo, motivando-o e sendo mais participativo e autônomo. Nas metodologias ativas "o aprendizado se dá a partir de problemas e situações reais; os mesmos que os alunos vivenciarão depois na vida profissional, de forma antecipada, durante o curso" (MORAN, 2015, p. 19).

Ressalta-se que as metodologias ativas fazem parte dos estudos de muitos teóricos da Educação há bastante tempo, com destaque para Paulo Freire (2011), que defende uma educação libertadora, não bancária, na qual o estudante seja protagonista. Conforme Bastos (2006) "metodologias ativas são processos interativos de conhecimento, análise, estudos pesquisas e decisões individuais ou coletivas, com a finalidade de encontrar soluções para um problema". Quando se fala em metodologias ativas "estamos afirmando que o ensino por investigação, o uso de tecnologias, do teatro, a aprendizagem por problemas, o trabalho de campo as aulas cooperativas" (MORAES, 2017, p. 81) têm como foco o aprendizado do estudante. Sob esta perspectiva, são utilizadas metodologias ativas nas práticas pedagógicas que possuem mediação das tecnologias, por possuírem características que estimulam a autonomia, a iniciativa, e, por consequência, o protagonismo dos indivíduos envolvidos.

A sala de aula invertida, utilizada na pesquisa, é conceituada por Bergmann e Sans da seguinte maneira: "o que tradicionalmente é feito em sala de aula, agora é executado em casa, e o que é tradicionalmente feito como trabalho de casa, agora é realizado em sala de aula" (2016, p. 1). Nesse método, o uso das TDIC auxilia no processo de construção do conhecimento, pois os estudantes são estimulados a utilizar os dispositivos computacionais e seus recursos para a realização da atividade. Dessa forma, em casa os estudantes leem os textos, assistem aos vídeos e slides, enfim, tomam conhecimento de todo o material que o professor disponibilizou para a aula e, concomitante a isso, fazem as anotações dos conceitos não entendidos e possíveis questionamentos. Já na sala de aula, em espaço escolar, haverá discussões referentes ao assunto, a problematização e a construção de soluções.

Para realização das atividades da pesquisa sob o método da sala de aula invertida, a dinâmica da aula foi a seguinte: 


\section{Autuaŗão}

ISSN: 1984-6444 | http://dx.doi.org/10.5902/1984644429807

a) criou-se um grupo fechado com os estudantes, na rede social da preferência deles, Facebook, para disponibilizar o material das aulas. Neste grupo foram disponibilizados textos e vídeos sobre o conteúdo trabalhado. No grupo também eram realizadas conversas entre pesquisador e estudantes para explicações relativas ao material a ser analisado;

b) em casa, enquanto os estudantes tomavam conhecimento do material disponibilizado, anotaram suas dúvidas e o que encontraram de mais significativo no material;

c) em sala de aula, o pesquisador apresentou a problematização do assunto, dividiu a turma em grupos e orientou-os a elencar três elementos que fossem fundamentais para a compreensão do assunto e auxiliar na resposta da questão norteadora; esses elementos foram denominados pontos-chave;

d) as anotações de cada grupo foram realizadas em um documento compartilhado com o pesquisador;

e) a atividade seguinte foi pesquisar os pontos-chave para obter as informações necessárias à resposta do questionamento; essa atividade foi realizada com auxílio de computadores e celulares conectados à internet, bem como o acompanhamento do professor pesquisador nos grupos;

f) por fim, os estudantes elaboraram e apresentaram suas conclusões aos colegas; a forma como as apresentações foram feitas foi de escolha de cada grupo.

Os resultados obtidos com a avaliação da atividade serão apresentados no item 4 intitulado: A metodologia ativa na aula de Geografia estimulando o protagonismo juvenil.

É importante destacar que o processo cognitivo de construção do conhecimento e aprendizagem não muda, no entanto, a maneira como se tem acesso às informações que serão transformadas em conhecimento e os mecanismos de aprendizagem mudam com o avanço das tecnologias, principalmente com o acesso a elas.

Na sociedade tecnológica em que se vive, informações de todos os tipos estão disponíveis em rede, basta um suporte (computador, tablet ou celular) para acessá- 


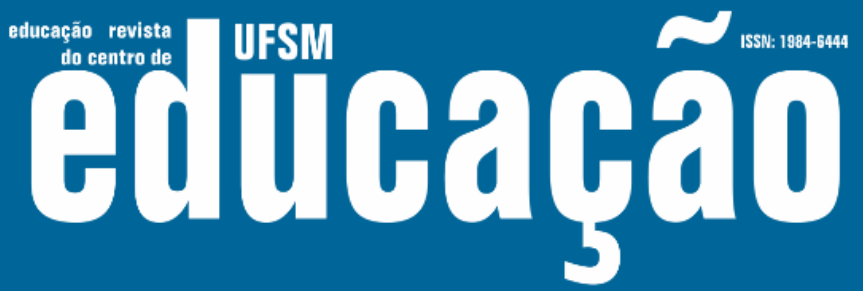

ISSN: 1984-6444 | http://dx.doi.org/10.5902/1984644429807

las. Porém, nem todas são confiáveis; nesse ponto chama-se a atenção para a importância do letramento digital dos professores, pois é por meio do conhecimento de como utilizar as tecnologias digitais em suas aulas que os professores terão condições de realizar alterações nas metodologias e com isso poder auxiliar os estudantes na escolha e interpretação dessas informações.

Um dos desafios da escola contemporânea constitui-se em selecionar e transformar a enxurrada de informações que se encontra disponível, de maneira desorganizada e fragmentada nos meios digitais, em conhecimento. Para tal são necessárias mudanças significativas nos processos educativos na escola como um todo, incluindo metodologia de ensino, espaço físico, mudança das práticas dos professores, diretores e também dos governos que dão o suporte financeiro para que realmente se efetivem.

É relevante lembrar que a rede é "um conjunto de nós interconectados" (CASTELLS, 2003, p. 7) e a internet, como tal, recebe informações dos diversos nós que a compõem e cabe aos usuários desta rede a seleção das informações que lhes são mais convenientes. Além disso, e tão importante quanto, é saber o que fazer com essas informações para que elas possam ser transformadas em conhecimento e quem sabe, ser mais um nó da rede.

A sociedade tecnológica, com suas frenéticas mudanças, depara-se com uma estrutura muito resistente ainda, que, apesar de estar completamente imbricada na sociedade, não consegue modificar-se para acompanhar a evolução e tirar proveito dela. Essa estrutura é a escola, que, conforme sugere Sibilia (2012, p. 13), "é uma tecnologia de outra época".

É necessário o entendimento de que existem, sim, novas formas de ensinar e também de aprender. Se há alguns anos o professor era o único detentor do conhecimento e a socialização deste era feita através de recursos mnemônicos, isso mudou. Os estudantes hoje têm mais acesso às informações, muita interação, colaboração, compartilhamento, enfim, mudanças que foram ocorrendo com a evolução tecnológica que permeia a sociedade.

Com a realização desta pesquisa foi possível elaborar o perfil do jovem estudante do Ensino Médio, a partir de uma visão sociocultural, a qual o outro social 


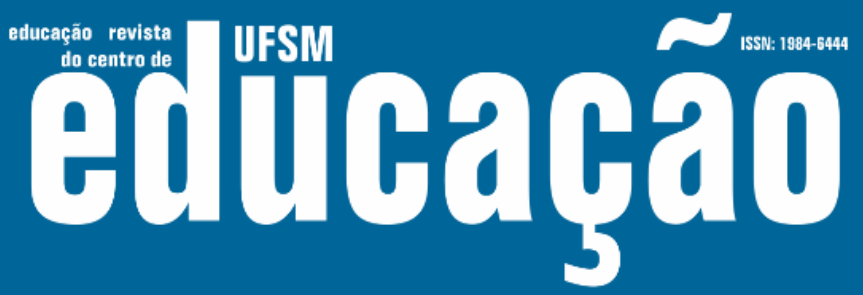

ISSN: 1984-6444 | http://dx.doi.org/10.5902/1984644429807

(neste caso entende-se o outro como o (s) professor (es)) tem papel de mediador no processo de aprendizagem e construção do conhecimento, para que possa haver o desenvolvimento desse indivíduo.

O jovem do século XXI tem habilidades múltiplas com dispositivos eletrônicos, é conectado à rede de computadores onde vive imerso, praticando atividades de lazer e também se relacionando com as pessoas. Pesquisa suas inquietações e curiosidades nesta rede, porém desenvolve uma cultura da superficialidade, uma vez que suas leituras são baseadas em textos breves e pouco profundos. Essa disponibilidade e fácil acesso às informações faz com que se desenvolva uma ânsia para que tudo seja resolvido imediatamente, sem pensar muito no amanhã.

Entende-se que a partir desse perfil de jovem seja possível uma visão panorâmica, porém não linear, devido às especificidades existentes, em cada região do país, do estudante do Ensino Médio. Com isso, promover possíveis mudanças que levem em conta os métodos utilizados nas escolas, e também o estímulo ao desenvolvimento do protagonismo juvenil, assunto este que será desenvolvido no próximo item do texto, antes de apresentarmos os resultados da prática metodológica desenvolvida.

\section{O protagonismo social do jovem estudante do ensino médio}

Para contextualizar e fundamentar o protagonismo social do jovem estudante do Ensino Médio, recorte da pesquisa realizada, utilizou-se Lei de Diretrizes e Bases da Educação Nacional (LDB) ${ }^{1}$ de 1996; a Constituição Federal Brasileira de 1988, art. $3^{\circ}$, que apresenta os objetivos da República Federativa do Brasil; Diretrizes Curriculares Nacional para o Ensino Médio - DCNEM de 2012; Referencial Curricular do Ensino Médio no Rio Grande do Sul, Ciências Humanas e suas Tecnologias, bem como a concepção de protagonismo social elaborada por Costa $(2000,2006)$.

Antônio Carlos Gomes da Costa, um dos estudiosos do protagonismo social do jovem no Brasil e também um dos redatores do Estatuto da Criança e do Adolescente (ECA) de 1990, defendia uma educação que pudesse proporcionar protagonismo ao jovem, na qual ele pudesse ser fonte de iniciativa, liberdade e compromisso. Ou seja, 


\section{Eutha \\ 15SN: 1984-6444

ISSN: 1984-6444 | http://dx.doi.org/10.5902/1984644429807

o jovem envolver-se no processo pedagógico, não ser somente receptor ou espectador, mas poder decidir e fazer suas opções e também ter responsabilidade pelos seus atos e escolhas.

A escola como espaço de produção do conhecimento sistematizado precisa proporcionar ao estudante condições para que ele possa desempenhar "o papel de sujeito da produção de sua inteligência do mundo e não apenas o de recebedor da que the seja transferida pelo professor" (FREIRE, 2011, p. 121). É, pois, nesse universo que jovens de diferentes meios sociais, poderão trabalhar sua autonomia, iniciativa, responsabilidade e compromisso com vistas ao desenvolvimento do protagonismo social.

A concepção de protagonismo social adotada neste texto é a desenvolvida por Gomes da Costa, onde defende que como modalidade de ação educativa o protagonismo juvenil é "a criação de espaços e condições capazes de possibilitar aos jovens envolver-se em atividades direcionadas à solução de problemas reais, atuando como fonte de iniciativa, liberdade e compromisso" (COSTA, 2000, p.06).

É importante ressaltar que o conceito de protagonismo juvenil é passível de diferentes interpretações, porém o enfoque neste texto é a questão de o jovem, estudante do Ensino Médio regular, ter responsabilidades, poder opinar e decidir no processo de aprendizagem. Para que tal aconteça, a função mediadora do professor, como organizador de situações significativas de aprendizagem, é fundamental; e, nesse processo, as tecnologias digitais podem trazer grande contribuição, principalmente no que diz respeito à motivação e ao desenvolvimento de competências cognitivas complexas, visando a formação de jovens autônomos e protagonistas de mudanças sociais, para o que o conhecimento geográfico é essencial.

Conforme o Referencial Curricular do Ensino Médio no Rio Grande do Sul Ciências Humanas e suas Tecnologias, os objetivos propostos para esse nível de ensino baseiam-se em três eixos, que levam em conta as capacidades de: representar e comunicar, investigar, compreender e contextualizar social e historicamente os conteúdos trabalhados. 


\section{Wusm FutlaghaO}

ISSN: 1984-6444 | http://dx.doi.org/10.5902/1984644429807

Para estimular o desenvolvimento dessas capacidades é necessário que se articulem os conhecimentos novos aos conhecimentos prévios já existentes na estrutura cognitiva do aprendiz; a partir dessa articulação instigar a autonomia, a iniciativa, a responsabilidade e o compromisso do jovem, como formação para "a atuação criativa, construtiva e solidária do jovem, junto a pessoas do mundo adulto (educadores), na solução de problemas reais na escola, na comunidade e na vida social mais ampla" (COSTA; VIEIRA, 2006, p. 22).

\section{Metodologias ativas na aula de geografia estimulando 0 protagonismo juvenil}

O desenvolvimento do meio técnico/científico contribuiu e continua contribuindo muito para os estudos da Geografia. Na graduação, o futuro professor de Geografia conhece as geotecnologias, dentre elas o sensoriamento remoto e a informática, ferramentas que auxiliam na construção dos Sistemas de Informação Geográfica (SIG), as quais proporcionaram grandes mudanças na forma de analisar o espaço geográfico. Porém, nem sempre a utilização é estendida aos estudantes da educação básica, devido principalmente ao alto valor dos equipamentos e softwares necessários, bem como a formação mais específica dos professores para utilização desses.

No entanto, existem outras opções disponíveis e mais acessíveis, como as ferramentas on-line encontradas nas TDIC; uma delas é o Google Earth, programa gratuito disponível para download. Com a utilização desse e de outros programas disponíveis em rede e de acesso gratuito nas aulas de Geografia do Ensino Médio, é possível a observação das mudanças que ocorrem no espaço a partir do tempo, pois além de possibilitar a visualização do ambiente estudado, "com possibilidade de aproximação e distanciamento, sobrevoo, observação de edificações, algumas em 3D" (PEREIRA, 2010, p. 53), até mesmo em datas diferentes, permite a análise das transformações ocorridas nos últimos anos nos diversos espaços geográficos. Dessa maneira, as condições de interpretação e possíveis intervenções podem potencializar- 


\title{
T Wsm Eutoraba
}

ISSN: 1984-6444 | http://dx.doi.org/10.5902/1984644429807

se; essa atividade, porém, só terá êxito se houver uma mediação adequada do professor, que leve a esse entendimento. Nesse sentido, destaca-se o papel do professor de Geografia, que irá proporcionar condições para que o estudante construa o conhecimento em relação ao tema estudado e à ferramenta utilizada.

A vida em sociedade é permeada por conhecimentos geográficos que, por vezes, passam despercebidos, por isso a grande importância de a Geografia escolar trabalhar questões de interpretação e problematização espaço/temporal com os estudantes. Cavalcante enfatiza a importância da Geografa escolar para formação do aluno:

\begin{abstract}
O trabalho da educação geográfica ajuda os alunos a desenvolverem modos do pensamento geográfico, a internalizarem métodos e procedimentos de captar a realidade tendo consciência de sua espacialidade. Esse modo de pensar geográfico é importante para a realização de práticas sociais variadas, já que essas práticas são sempre práticas sócio-espaciais. A materialização dessas práticas que se realizam num movimento entre as pessoas e os espaços vai se tornando cada vez mais complexa, e sua compreensão cada vez mais difícil, o que requer referências conceituais sistematizadas, para além de suas referências espaciais cotidianas, carregadas de sentidos, de história, de imagens, de representações. (CAVALCANTI, 2008, p. 36).
\end{abstract}

A construção do conhecimento em Geografia de maneira significativa na educação básica perpassa pelo trabalho do professor. É ele quem irá articular o conhecimento referente à ciência geográfica, às metodologias de ensino e aos conteúdos específicos a serem desenvolvidos de modo que o estudante possa associar as discussões realizadas em aula ao seu contexto social.

Pautar a atividade profissional do professor de Geografia somente à reprodução teórica não condiz com a realidade a qual se vive, porém, reduzir as aulas ao senso comum também não. É necessário fazer a relação entre a ciência e a vida em sociedade, pois o conhecimento científico é materializado ou se materializa a partir da sociedade. Assim, as novas necessidades do mundo do trabalho apresentam novas demandas para o exercício da docência, conforme Kuenzer:

Ao professor não basta conhecer o conteúdo específico de sua área; ele deverá ser capaz de transpô-lo para situações educativas, para o que deverá conhecer os modos como se dá a aprendizagem em cada etapa do desenvolvimento humano, as formas de organizar o processo de aprendizagem e os procedimentos metodológicos próprios de cada conteúdo. (KUENZER, 2013, p. 94). 


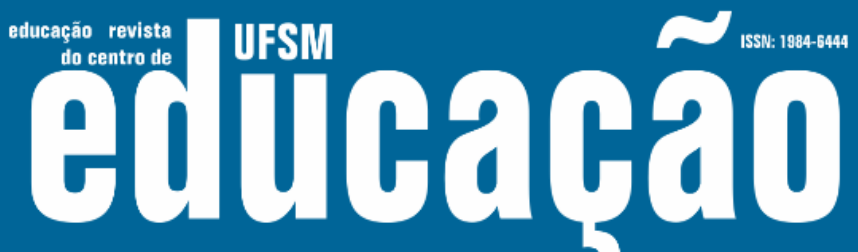

ISSN: 1984-6444 | http://dx.doi.org/10.5902/1984644429807

A partir dessa realidade reitera-se a importância da utilização das TDIC nas aulas de Geografia, visto que as mesmas possuem grande potencial para estabelecer relações entre os conceitos científicos e a vida em sociedade. Sociedade essa que clama por direito à inclusão em todos os sentidos, ou seja, inclusão de pessoas com necessidades especiais, inclusão de cidadãos em situação de conflito com a lei, inclusão de pessoas excluídas do trabalho, inclusão de pessoas de diferentes etnias, e outas tantas que não se entendem como sujeitos de direitos. Enfim, a sociedade diversa proporcionando, através do uso das tecnologias digitais nas aulas de Geografia, o direito ao acesso aos meios que permitem compreendê-la e transformála.

Contudo, a utilização das TDIC na perspectiva acima enunciada, demanda domínio teórico específico, domínio pedagógico e domínio tecnológico, do contrário corre-se o risco de apenas trocar o suporte para o desenvolvimento e anotações das aulas: o quadro de giz e o caderno pelo tablet, computador ou smartphone.

A seguir, apresentam-se os resultados da avaliação do método "sala de aula invertida", realizados pelos estudantes que participaram da atividade. Eles responderam a onze questões, sendo três descritivas e oito objetivas; as respostas aqui apresentadas são das questões descritivas.

A primeira questão apresentada aos estudantes foi: Você se sentiu mais ou menos envolvido com os trabalhos realizados nas aulas em que utilizamos as tecnologias digitais para a realização das atividades? Por quê?

\section{Respostas dos estudantes da escola A - 15 respostas}

Sim, pois já conhecemos esse mundo das tecnologias, e acabou auxiliando na nossa aprendizagem, usando meios mais evolutivos para trabalhar na sala.

Mais envolvido, pois as tecnologias digitais permitem uma aproximação maior da realidade estudada, contribuindo assim para um melhor desenvolvimento do conhecimento.

Mais envolvido, pois encontramos mais informações a partir dos trabalhos e mais conhecimento. 


\section{Uism

ISSN: 1984-6444 | http://dx.doi.org/10.5902/1984644429807

Mais, pois conseguimos encontrar mais informações e utilizar das tecnologias da nossa escola, mesmo não sendo das melhores.

Sim, porque o assunto foi realmente interessante e acabou despertando a vontade de aprender mais sobre o continente africano e foi através da tecnologia que tivemos um avanço muito grande no conhecimento, aprendemos coisas que jamais imaginaríamos que existia.

Sim, pois hoje a tecnologia faz parte do nosso cotidiano.

Sim, o uso das tecnologias foi de grande importância, e trouxe mais facilidade para o êxito dos trabalhos realizados.

Sim, porque tinha acesso fácil.

Mais, por causa das pesquisas.

Sim, porque tivemos mais oportunidade de pesquisa e mais envolvimento com o conteúdo.

Sim, pois o uso das tecnologias atrai mais a atenção dos alunos já que estes vivem conectados com o mundo virtual.

Mais, pois aumentou a participação e o interesse por parte dos alunos.

Me senti envolvida com o trabalho, já que utilizamos bastante a tecnologia que está sempre presente. A proposta de envolver o trabalho com a tecnologia foi ótima.

Me senti muito mais envolvida, até porque a tecnologia é uma coisa que está muito presente em nosso dia a dia, facilitando e tirando dúvidas existentes.

Sim, pois obtive mais conhecimentos sobre esse assunto e aprendi de um modo melhor.

\section{Respostas dos estudantes da escola B -12 respostas} Mais.

Me senti envolvida nas aulas, pois o assunto foi bastante fluente. Mais.

Sim, até pela facilidade de entendimento dos assuntos debatidos!

Sim, pois trabalhando em grupo adquirimos mais conhecimentos sobre 0 assunto. 


\section{D usm

ISSN: 1984-6444 | http://dx.doi.org/10.5902/1984644429807

Sim, porque eu consegui utilizar as tecnologias de uma forma diferente.

Sim, porque é mais prático acessível.

Sim.

Sim, porque utilizamos a tecnologia de outra forma.

Sim porque a maioria dos adolescentes usa os meios tecnológicos e isso contribuiu mais para o meu desenvolvimento escolar.

Sim porque as aulas foram bem envolventes e foram bem explicadas, então me senti bem envolvido.

Me senti mais envolvido nas atividades, porque o uso da tecnologia auxilia em muito para a realização das aulas.

\section{Respostas dos estudantes da escola $\mathrm{C}-15$ respostas}

Mais envolvido, pois a internet facilita as pesquisas.

Me senti menos interessada. Com o uso da sala digital, é mais fácil para se distrair e eu me concentrei menos do que em aulas tradicionais.

Sim, pois é um sistema onde todos interagem e participam.

Sim porque com o auxílio de algumas tecnologias as aulas e até mesmo o conteúdo fica melhor e mais interessante de aprender.

Sim, pois é algo diferente mais ligado ao que a gente mais usa hoje em dia, além de agilizar as aulas/trabalhos propostos.

Sim, pois tivemos que se empenhar para pesquisar o conteúdo do grupo e foi até mais fácil para entender o conteúdo.

Mais envolvido.

Mais envolvido pelo fato de sair da sala e fazer coisas diferentes.

Mais envolvido, pois foi disposto de mais tempo em casa e assim o tema pode ser mais aprofundado.

Sim, pois isso é um novo aprendizado, um novo conhecer.

Mais, porque com o computador como meio de instrução auxiliando as pesquisas há mais facilidade de ter um resultado melhor.

Mais, porque saiu do tradicional.

Me envolvi muito no trabalho em que foi realizado nas aulas de geografia. 


\section{Autuaŗão}

ISSN: 1984-6444 | http://dx.doi.org/10.5902/1984644429807

Sim, porque fazer trabalhos através da internet envolve mais vontade de correr atrás e fazer, ao contrário de fazer sempre com a mesma metodologia.

Sim, pois essa é a nossa realidade e é um método diferente e muito bom de estudo.

Através das respostas dos estudantes é possível o entendimento de que eles realmente se sentiram mais envolvidos com as atividades realizadas com o auxílio das TDIC, somente um estudante disse que se sentiu menos interessado, pois é mais fácil distrair-se e que para ele a concentração é maior nas aulas tradicionais. É importante enfatizar que, além dos estudantes terem destacado maior participação, maior interação e envolvimento com o conteúdo, sobressai nas respostas o uso das TDIC de maneira diferente e também a questão de a tecnologia digital fazer parte do dia a dia deles e estar sendo utilizada na sala de aula.

Quando se fala em processos de ensino-aprendizagem, fazem-se presentes dois grandes teóricos: Paulo Freire e David Ausubel. O primeiro mostra em sua vasta bibliografia que não existe ensino sem aprendizagem e a importância de valorizar os saberes socialmente construídos pelos estudantes, nos espaços onde eles estão inseridos. O segundo enfatiza a questão da aprendizagem significativa, ou seja, o que influencia no processo de aprendizagem é levar em conta os conhecimentos já adquiridos pelo aprendiz. Assim, usar as TDIC como mediadoras em processos de ensino-aprendizagem de Geografia no Ensino Médio, além de ser um método de ensino que proporciona maior participação, interação e envolvimento dos estudantes com o conteúdo, como evidenciado nas respostas, a aprendizagem será mais significativa, pois os estudantes estão utilizando seus conhecimentos em relação às TDIC, para a construção do conhecimento geográfico, que Ihes proporcionará visão ampla da sociedade, estimulando o protagonismo social.

As próximas duas questões aqui analisadas referem-se aos pontos positivos e negativos das aulas de Geografia mediadas pelas TDIC. Para melhor entendimento apresentaremos em forma de quadro. 


\section{N

ISSN: 1984-6444 | http://dx.doi.org/10.5902/1984644429807

Quadro 01 - Estudantes da Escola 01 - Pontos Positivos e Negativos das aulas de Geografia mediadas pelas TDIC

\begin{tabular}{ll} 
PONTOS POSITIVOS & PONTOS NEGATIVOS \\
\hline Foi mais prático usar a sala digital para & O conteúdo não foi exposto de \\
as atividades. Podemos ter autonomia e & maneira clara, ficou confuso e \\
realizar o trabalho facilmente. & $\begin{array}{l}\text { incompleto. Não me sinto segura } \\
\text { sobre o conteúdo estudado e não } \\
\text { tenho um conhecimento formado } \\
\text { sobre. }\end{array}$
\end{tabular}

Poder escolher entre os temas um que Acredito que não tem nenhum ponto mais nos agrade, e a forma como negativo, pois todos interagiram bem. interagimos com os grupos.

$\begin{array}{ll}\begin{array}{l}\text { Aprendizagem nova, auxílio de } \\ \text { tecnologias nunca antes usadas na } \\ \text { matéria, conteúdo ótimo, professora } \\ \text { super aplicada, etc. }\end{array} & \begin{array}{l}\text { Deveria de ter mais aulas ou mais } \\ \text { prejudicaram o andamento das aulas } \\ \text { o resto foi muito positivo. }\end{array} \\ \begin{array}{l}\text { Mais integração com os componentes } \\ \text { do grupo fazendo com que assim todos problema é a falta de } \\ \text { colaboração de alguns estudantes. }\end{array}\end{array}$
que estavam participando fizessem sua parte e a agilidade na realização do trabalho.

Todos se empenharam bastante, pois como todos têm internet hoje em dia isso ajudou bastante para termos um bom resultado na hora de pesquisar

A oportunidade de envolver a matéria com as tecnologias dentro do ambiente escolar. Praticidade, novidade e possibilitou aos alunos sair da mesma monotonia de sempre!

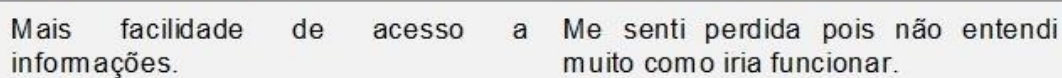
muito como iria funcionar.

Foram usados objetos eletrônicos na Em alguns momentos certos alunos elaboração dos trabalhos, houve muitas não colaboravam com a apresentação explicações de temas que foram dos colegas. apresentados em aula.

Os pontos positivos foi que alguns correram atrás e no meu grupo por exemplo, o trabalho foi em equipe!

Os pontos negativos foi que alguns grupos não se esforçaram muito com as tarefas solicitadas, portanto, 0 aprendizado não foi concluído com muito êxito sobre o assunto falado.

Fonte: Autores, 2017. 


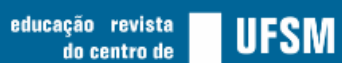 Gutrathá}

ISSN: 1984-6444 | http://dx.doi.org/10.5902/1984644429807

Quadro 02 - Estudantes da Escola 02 - Pontos Positivos e Negativos das aulas de Geografia mediadas pelas TDIC

\begin{tabular}{|c|c|}
\hline PONTOS POSITIVOS & PONTOS NEGATIVOS \\
\hline $\begin{array}{l}\text { Mais conhecimento sobre a } \\
\text { Revolução Industrial. }\end{array}$ & Nenhum (2). \\
\hline $\begin{array}{l}\text { Mais aprendizagem, e conhecimento } \\
\text { da Revolução Industrial. }\end{array}$ & Não teve pontos negativos. \\
\hline $\begin{array}{l}\text { Podemos aprender mais sobre o } \\
\text { assunto e tirar dúvidas. }\end{array}$ & $\begin{array}{l}\text { Na minha opinião não tiveram } \\
\text { pontos negativos, foi realmente } \\
\text { bom. }\end{array}$ \\
\hline $\begin{array}{l}\text { Acessibilidade, } \\
\text { debates. }\end{array}$ & Pouco tempo. \\
\hline $\begin{array}{l}\text { Podemos expor nossas ideias para os } \\
\text { nossos colegas adquirindo } \\
\text { questionários e conhecimento. }\end{array}$ & Não teve nenhum, eu acho. \\
\hline
\end{tabular}

Aprendi bastante, gostei das aulas, Nenhum. me interessei no conteúdo, trabalho com slides é muito melhor, e a professora explica bem!

É muito mais prático e mais Nenhum. interessante, não fica cansativo.

\begin{tabular}{lll}
\hline Entendimento; acessibilidade. & $\begin{array}{l}\text { Acho que não teve pontos } \\
\text { negativos. }\end{array}$ \\
\hline $\begin{array}{l}\text { Aprendi mais utilizando as } \\
\text { tecnologias, a professora explica bem, trabalhos. } \\
\text { utilizar slides é melhor para } \\
\text { compreendero conteúdo. }\end{array}$ & $\begin{array}{l}\text { Pode risco de perder } \\
\text { Aprendemos a usar melhor as Não achei pontos negativos, só } \\
\text { tecnologias nas aulas. }\end{array}$ \\
& $\begin{array}{l}\text { acho que deveriam ser mais } \\
\text { mostradas na mídia. }\end{array}$ \\
\hline
\end{tabular}

É mais prático e mais interessante, Não existem pontos negativos. bom para o conhecimento da população brasileira e bom para que todos se socializem.

Fonte: Autores, 2017. 


\title{
N U.s.

ISSN: 1984-6444 | http://dx.doi.org/10.5902/1984644429807

Quadro 03 - Estudantes da Escola 03 - Pontos Positivos e Negativos das aulas de Geografia mediadas pelas TDIC

\begin{tabular}{|c|}
\hline PONTOS POSITIVOS \\
\hline $\begin{array}{l}\text { Maior interação entre alunos, maior } \\
\text { responsabilidade. }\end{array}$ \\
\hline $\begin{array}{l}\text { Aproximação da realidade, trabalho com } \\
\text { documentários e imagens importantes } \\
\text { para uma melhor assimilação do } \\
\text { conteúdo. }\end{array}$ \\
\hline
\end{tabular}

Um ponto muito positivo é o fato de que acrescenta muito mais no nosso conhecimento e em nossas informações.

\begin{tabular}{|c|c|c|}
\hline $\begin{array}{l}\text { Avanço no } \\
\text { respondidas... }\end{array}$ & conhecimento, duvidas & $\begin{array}{l}\text { É pouco utilizada, e os objetos } \\
\text { tecnológicos que temos na escola } \\
\text { não se encontram em bom } \\
\text { funcionamento. }\end{array}$ \\
\hline
\end{tabular}

Quaisquer dúvidas foram resolvidas com o auxílio do professor, o que ajudou a formar uma opinião ampla sobre o assunto.

Tivemos a oportunidade de aproveitar o uso das tecnologias para um melhor rendimento na aprendizagem.

\section{Maior participação.}

A atividade desenvolvida propôs trabalharmos com tecnologias que temos presente no nosso dia a dia, foi bom colaborar com o grupo, assumir responsabilidades, ajudar um ao outro e expor nossas opiniões

\section{PONTOS NEGATIVOS}

Nenhum (2).

Aumento de faltas de colegas, falta de participação de alguns.

Um ponto ruim é que há pouca tecnologia digital em aulas de geografia, o que diminui a nossa possibilidade de ampliar nossos conhecimentos.

\section{Não teve.}

Desinteresse por parte de alguns alunos.

Falta de participação de alguns alunos.

Para mim as aulas não tiveram pontos negativos.

\begin{abstract}
Eu gostei muito dessas aulas de Geografia. Na verdade, muito mais do que as cotidianas. Só teve pontos positivos no meu ponto de vista, pois como já falei as tecnologias digitais facilitam muito a nossa vida.
\end{abstract}

Fonte: Autores, 2017.

Observando os quadros é possível o entendimento de que, na avaliação dos estudantes, são poucos os pontos negativos e, dentre os positivos, destacam-se as respostas que têm grande relação com autonomia, iniciativa, responsabilidade e o compromisso que são as categorias que compõem o protagonismo juvenil. 


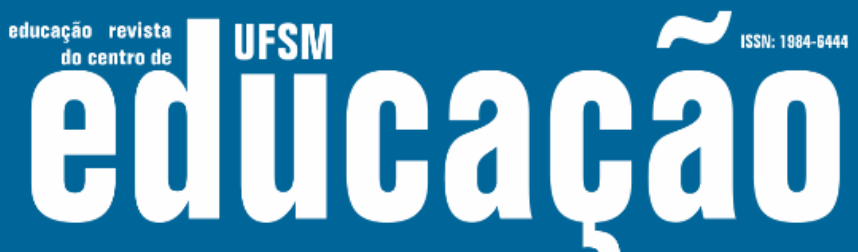

ISSN: 1984-6444 | http://dx.doi.org/10.5902/1984644429807

\section{Considerações finais}

Com a aplicação da metodologia sala de aula invertida constatou-se que houve estímulo ao protagonismo dos alunos, pois os estudantes sentiram-se mais envolvidos com o conteúdo, principalmente por poderem utilizar as TDIC nas atividades. Além disso, trabalhar em grupos proporcionou mais interação entre eles, pois tiveram que pesquisar, problematizar e decidir a socialização da atividade.

Entende-se que usar as TDIC como mediadoras em processos de ensino e aprendizagem de Geografia no Ensino Médio, além de ser um método de ensino que proporciona maior participação, interação e envolvimento dos estudantes com o conteúdo, como ficou evidenciado na pesquisa, promove aprendizagem mais significativa, pois os estudantes estão utilizando seus conhecimentos em relação às TDIC para a construção do conhecimento geográfico, o que lhes proporcionará visão ampla da sociedade, estimulando o protagonismo social.

Com base nessa perspectiva, destaca-se que aplicar metodologias baseadas no protagonismo do estudante e com utilização extensiva de tecnologias digitais em sala de aula estimula o protagonismo social do jovem, proporcionando maior autonomia, responsabilidade, iniciativa e compromisso com a sociedade. Os estudantes sentem-se protagonistas na construção do conhecimento, sendo fundamental a mediação pedagógica do professor nesse processo. Além de organizar situações para que o processo de ensino-aprendizagem ocorra, o professor tem condições de detectar possíveis erros de interpretação ocasionados pelo excesso de informações acessíveis a quem tem um suporte computacional conectado à internet.

Infere-se também que as TDIC podem ser consideradas mediadoras em processo de construção do conhecimento geográfico do estudante do Ensino Médio. Através de sua utilização em atividade de aula, os estudantes têm condições de conciliar o conhecimento já adquirido em relação às tecnologias digitais, por terem nascido em uma sociedade permeada por elas, para a construção de um novo conhecimento em relação à ciência, neste caso a Geografia. Com isso, é possível atribuir maior significado ao ato de aprender e ao processo de construção do 


\section{F HEM Eulloahá}

ISSN: 1984-6444 | http://dx.doi.org/10.5902/1984644429807

conhecimento, devido à ampliação de possibilidades proporcionadas pelas TDIC, como, por exemplo: a visualização, interação, colaboração e compartilhamento dos resultados obtidos.

Contudo, entende-se que para isso as atividades têm de ser adequadamente preparadas, para o que os docentes devem estar qualificados, ou seja, ter o letramento digital para utilização das TDIC em atividades de aula.

Na realização da atividade relatada, foi possível constatar que, nas aulas em que os recursos tecnológicos foram explorados pelo pesquisador, os estudantes foram instigados a procurar as informações, problematizar, associá-las ao que estava sendo estudado, construir seu próprio conhecimento em relação ao assunto e também socializá-lo aos colegas. Ou seja, protagonizando a construção do conhecimento e não sendo meros receptores de informações repassadas pelo professor.

Embora no início das atividades elaboradas para a aula mediada pelas TDIC os estudantes tenham se sentido pouco confortáveis com a questão de ter que pesquisar, ler os textos, avaliar o material, assistir vídeos, compartilhar, enfim, sair da condição de receptores de informações para emissores e socializadores, ao final, foram unânimes em avaliar a atividade como estimuladora do protagonismo juvenil, principalmente no que diz respeito ao compromisso com a sociedade, à noção de que todos têm responsabilidade na comunidade onde estão inseridos, independentemente de serem jovens.

Ressalta-se que trabalhar a criticidade, estimular a inteligibilidade da complexidade do real e também incentivar a desinibição dos jovens é papel da escola; portanto, é importante que se "instigue constantemente a curiosidade do educando em vez de 'amaciá-la' ou 'domesticá-la'. É preciso mostrar ao educando que o uso ingênuo da curiosidade altera a sua capacidade de achar e obstaculiza a exatidão do achado" (FREIRE, 2011, p. 121).

Sob essa visão, conclui-se que o uso das TDIC como mediadoras em processos de ensino e aprendizagem de Geografia no Ensino Médio, além de proporcionar maior envolvimento do estudante com o conteúdo é um estimulador do protagonismo juvenil. Porém, enfatiza-se a necessidade da utilização de metodologias específicas para estas aulas, pois, do contrário, corre-se o risco de entender as TDIC 


\section{工 Wism Eutlaghat}

ISSN: 1984-6444 | http://dx.doi.org/10.5902/1984644429807

como mudança de suporte para desenvolvimento das aulas, do quadro de giz para o projetor.

\section{Referências}

BASTOS, Celso da Cunha. Educação e Medicina. Blog, 2006. Disponível em: http://educacaoemedicina.blogspot.com.br/2006/02/metodologias-ativas.html

BERGMANN, Jonathan; SAMS, Aaron. Sala de aula invertida: uma metodologia ativa de aprendizagem. Rio de Janeiro: LTC, 2016.

BRASIL. Ministério da Educação e Cultura. Ciências humanas e suas tecnologias. Secretaria de Educação Básica. Brasília: Ministério da Educação, Secretaria de Educação Básica, 2006. 133 p. (Orientações curriculares para o ensino médio; volume 3) Disponível em: http://portal.mec.gov.br/seb/arquivos/pdf/book_volume_03_internet. pdf. Acesso em: jan. 2016.

BRASIL. Constituição da República Federativa do Brasil de 1988. Disponível em: http://www.planalto.gov.br/ccivil_03/constituicao/constituicaocompilado.htm. Acesso em: ago. 2016

BRASIL. Lei 9.394/1996. Diretrizes e Bases da Educação Nacional. Disponível em: http://www.planalto.gov.br/ccivil_03/Leis/L9394.htm.

BRASIL. Ministério da Educação. Diretrizes curriculares gerais da educação básica. Brasília: MEC, SEB, DICEI, 2013. Disponível em: http://portal.mec.gov.br/index.php?option=com_docman\&view=download\&alias=1554 7-diretrizes-curiculares-nacionais-2013-pdf-1\&ltemid=30192. Acesso em maio.2017.

CASTELLS, Manuel. A galáxia da internet: reflexões sobe a internet, os negócios e a sociedade. Rio de Janeiro: Zahar Editor, 2003.

CAVALCANTI, Lana de Souza. A geografia escolar e a cidade: ensaios sobre o ensino de geografia para a vida urbana cotidiana. Campinas: Papirus, 2008.

COSTA, Antonio Carlos Gomes da. Protagonismo juvenil: o que é e como praticálo. 2000. Disponível em: http://www.institutoalianca.org.br/Protagonismo_Juvenil.pdf. Acesso em: 15 out. 2016.

COSTA, Antonio Carlos Gomes da; VIEIRA, Maria Adenil. Protagonismo juvenil: adolescência, educação e participação democrática. São Paulo: FTD; Salvador, BA: Fundação Odebrecht, 2006.

FREIRE, Paulo. Pedagogia da autonomia: saberes necessários a prática educativa. São Paulo, SP. Paz e Terra, 2011. 


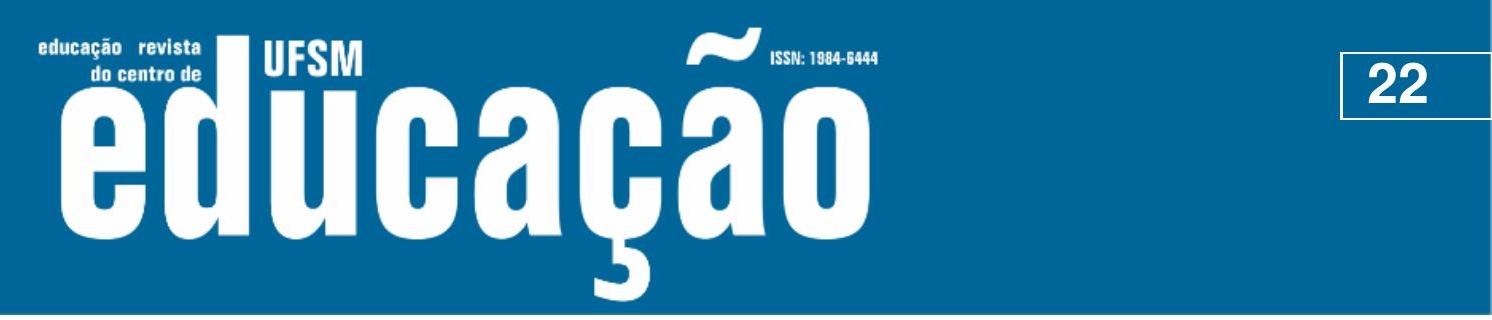

ISSN: 1984-6444 | http://dx.doi.org/10.5902/1984644429807

KUENZER, Acacia Zeneida. Dilemas para a formação e professores para o ensino médio no século XXI. In: AZEVEDO, J. C. de; REIS, J. T. (org.). Reestruturação do ensino médio. São Paulo: Fundação Santillana, 2013. Disponível em: http://www.senac.br/conhecimento/boletim-tecnico-do-senac.aspx. Acesso em: fev. 2017.

LACOSTE, Yves. A Geografia - Isso serve, em primeiro lugar, para fazer a guerra. Tradução Maria Cecilia França - 19aㅡ ed. Campinas, SP: Papirus, 2012.

MORAES, Jerusa Vilhena de. O papel das metodologias ativas no processo de alfabetização científica em Geografia. In ASCENÇÃO, Valéria de O. R.[et al] (org.) Conhecimentos de Geografia: Percursos de formação docente e práticas na Educação Básica. Belo Horizonte, MG: IGC, 2017

MORAN, José. Mudando a Educação com metodologias ativas. In SOUZA, Carlos A. de, MORALES, Ofélia E. T. (Org.) Convergências Midiáticas, Educação e Cidadania: aproximações jovens. Vol. II. Ponta Grossa: UEPG- PROEX, 2015. Disponível em: http://www.youblisher.com/p/1121724-Colecao-MidiasContemporaneas-Convergencias-Midiaticas-Educacao-e-Cidadania-aproximacoesjovens-Volume-II/. Acesso em Maio 2017.

PEREIRA, Ana Maria de Oliveira. O potencial das tecnologias de rede na construção do conhecimento geográfico. 123p. Dissertação (Mestrado em Educação), Universidade de Passo Fundo, Passo Fundo, 2010. Disponível em: https://secure.upf.br/tede/tde_busca/index.php. Acesso em Jun. 2017.

RIO GRANDE DO SUL. Referencial curricular ciências humanas e suas tecnologias. V5. Disponível em: http://www.educacao.rs.gov.br/pse/html/refer_curric. jsp?ACAO=acao1. Acesso em: abril. 2017.

SIBILIA, P. Redes ou paredes: a escola em tempos de dispersão. Rio de Janeiro: Contraponto, 2012.

\section{Correspondência}

Ana Maria de Oliveira Pereira - Universidade Federal da Fronteira Sul (UFFS). RS 135, km 72, 200, Caixa Postal 764, CEP 99700-970, Erechim, Santa Catarina, Brasil.

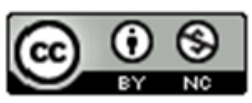

This work is licensed under a Creative Commons Attribution-NonCommercial 4.0 International (CC BY-NC 4.0) 


\title{
7 usm Jilloarga
}

ISSN: 1984-6444 | http://dx.doi.org/10.5902/1984644429807

\section{Notas}

\begin{abstract}
${ }^{1}$ Alteração realização através da Lei no 12.796 , de 4 de abril de 2013, a qual torna a educação básica obrigatória e gratuita dos 4 aos 17 anos. Disponível em: http://www.planalto.gov.br/ccivil_03/_Ato20112014/2013/Lei/L12796.htm\#art1
\end{abstract}

